\title{
The Case for a Middle Ground
}

\section{Thomas E. Elkins, MD}

Chief, Gynecology Division

Department of Obstetrics and Gynecology

University of Michigan Medical School

Ann Arbor, Michigan
$\mathbf{M}$ aternal-fetal conflict is a relatively new and mysterious phrase that is being applied to more and more medical-ethical-legal dilemmas in obstetric care. It describes such situations as legally mandated treatment programs for alcohol abuse in pregnancy, punitive legal action for cocaine abuse in pregnancy, decisions to perform (at significant maternal risk) in utero surgery for fetal anomalies, and even court-ordered cesarean sections to benefit the viable fetus. Not unrelated are the numerous issues surrounding abortion and prenatal genetic counseling. Rather than the traditional (mis)conception of a passive woman willing to give birth to a healthy child at any cost, the contemporary American woman occasionally resists health care that appears overly restrictive, intrusive, invasive, or threatening to her when fetal well-being is in question. Such situations seem to amplify an increasingly common conflict between mother and fetus. A brief look at the court-ordered cesarean section issue highlights these situations and gives a basis for the emotion and distress they foster.

1. Prominent ethical and legal concerns about privacy, bodily integrity, and autonomy are held to be near absolutes in a free society. ${ }^{1}$ In health care, this has been translated into a strong doctrine of informed consent and an emphasis on each competent person's right to refuse medical treatment. ${ }^{2}$ An extreme autonomy stance places the physician in the role of an obstetric technician whose only task is to assess patient competency and whose duty is to perform the competent patient's wishes or refer her to someone who will.

2. Retrospective reviews have revealed errors in diagnostic accuracy that have led to forced cesarean section. ${ }^{3}$ Some claim that in utero assessment is simply not exact enough ever to allow using such parameters to force treatment against someone's will.

3. The dominant place of the mother in comparison with the fetus in obstetric decision making is also championed by many, even at near-term gestation. Rights theorists give little philosophic justification to any concept of fetal rights. ${ }^{4}$ The most extreme position sees only one patient (the mother) to whom the fetus belongs as property. ${ }^{5}$

4. Finally, arguments are made that incorporate broader concerns than simply a single situation. Authors have tried to make settings where forced cesarean sections were considered analogous to other settings of interdependence (such as a sibling's need for a bone transplant) in which no court has ever forced organ donation or surgery on one person for the benefit of an- (c) 1990 by The Jacobs Institute of Women's Health $1049-3867 / 90 / \$ 3.50$ 
other. Some also fear the wide effects of such decisions, the "slippery slopes," that will force harsh restrictions on maternal behavior and discourage women from seeking prenatal care. ${ }^{6,7}$

Despite these very convincing arguments, court-ordered cesarean sections have occurred, and may, on occasion, continue. Alternative views have their own justifications.

1. The value of the fetus in our society, especially beyond viability and near term gestation, has long been recognized. This value is translated by some into an extreme sanctity of life view that is protective of the fetus at any gestational age. More common, however, has been the view expressed in Roe $v$. Wade of a state-supported vested interest in the well-being of the viable, third-trimester fetus. ${ }^{8}$ This has been expanded in many states to include feticide laws (making death of the viable fetus from any cause a punishable offense) and/or antiabortion laws (that prevent abortion on demand beyond a given gestational age). Therefore, beneficence-based actions to aid the fetus (or mother and fetus) with what appears to be a medically indicated cesarean section may arise from the will to do "the good" for a fetus that is valued even in utero, or for the fellow citizen that will soon exist. ${ }^{9}$

2. Others cite the obstetric uniqueness of the maternal-fetal relationship at term gestation as being a justification for forced intervention for the benefit of the mother and/or fetus. Contemporary advances in fetal surveillance techniques have clearly elevated the viable fetus to a status of "patienthood," and few would argue about the total dependency of fetus upon mother or about the unique interdependency at that point shown by maternal-fetal bonding data. ${ }^{10}$ Those who propose therapy directed at the patient's (or perhaps in this case, patients') best interests are compelled to consider both mother and fetus at term in contemporary obstetrics. ${ }^{11}$

3. Despite claims of in utero diagnostic inaccuracy, few would deny that occasions do exist when damage to a newborn infant as a result of nonintervention can be predicted with reasonable certainty. The benefit of surgical intervention far outweighs the burden to family, to society, and to the individual harmed when such a situation exists (as in the situation where a woman refuses cesarean delivery for a breech fetus with cephalic hyperextension, in which vaginal delivery carries a high rate of spinal cord transection and quadriplegia for the newborn).

4. Finally, contemporary data concerning maternal risks for delivery, either done vaginally or abdominally, do not always support refusal of cesarean delivery on a risk basis alone. Recent surveys from Massachusetts, for example, showed a much higher maternal mortality rate from vaginal deliveries when compared with cesarean deliveries. ${ }^{12}$ Once pregnancy has advanced to near-term gestation, no delivery method is entirely safe or painless, as has been implied by some authors totally opposing forced or coerced cesarean deliveries. The majority of "maternal-fetal conflict" cases involving cesarean deliveries actually involves "maternal-physician conflict" over the mode of delivery, when both parties are hoping for a healthy newborn (and fetus).

Regardless of one's viewpoint, few would consider the court system an ideal medical consult of last resort. Arbitrariness, time delays, and public notoriety make courts very unappealing decision makers. Although a court decision may prevent criminal liability, civil claims against physicians are rarely preventable regardless of the decision maker. In the 1990s, the role of ethics committees may supplant the use of court hearings in different cases.

In light of the aforementioned arguments, general agreement exists that court-ordered cesarean deliveries should be exceedingly rare events. However, certain instances make the term "never" unreasonable. Rarely, when 
treatment refusal is the issue, a woman's decisional capacity or competency may be difficult to determine, or the reasonable certainty of a tragic outcome for fetus, newborn, and/or mother may be unavoidable without intervention; or a woman may be honestly seeking aid to destroy a term fetus, making requests for court-ordered intervention appear a necessity for many.

The common factor in many cases of court-ordered cesarean delivery has been an absent, or a deficient doctor-patient relationship prior to a delivery room crisis. Improved prenatal counseling perhaps holds the key to most issues now discussed under the heading of maternal-fetal conflict. Regardless of the strong emotionally charged opinions on both sides of these arguments, careful analysis and individualized management of patient situations will still be necessary.

\section{REFERENCES}

1. Hallisey PL. The fetal patient and the unwilling mother: A standard for judicial intervention. Pacific Law J 1983;14:1065-78.

2. Nelson LJ, Milliken N. Compelled medical treatment of pregnant women: Life, liberty, and law in conflict. JAMA 1988;259:1060-6.

3. Kolder VE, Gallagher J, Parsons MT. Court-ordered obstetrical interventions. N Engl J Med 1987;316:1192-6.

4. Gallagher J. Prenatal invasions and interventions: What's wrong with fetal rights. Harvard Women's Law 1987;10:9-58.

5. Andrews L. My body, my property. Hastings Cent Rep 1986;16:28-38.

6. Holder AR. Maternal fetal conflicts and the law. Female Patient 1985;10:80.

7. American College of Obstetricians and Gynecologists. Patient choice: Maternalfetal conflict. American College of Obstetricians and Gynecologists policy statement. Washington, DC: The American College of Obstetricians and Gynecologists, 1987.

8. Roe v. Wade, 410 US 113 (1973).

9. Cervenak FA, McCullough LB. Perinatal ethics: A practical analysis of obligation to mother and fetus. Obstet Gynecol 1985;66:442-6.

10. Lenow JL. The fetus as a patient: Emerging rights as a person? Am J Law Med 1983;9:1-29.

11. American Academy of Pediatrics Committee on Bioethics. Fetal therapy: Ethical considerations. Pediatrics 1988;81:898-9.

12. Sachs BP, Yeh J, Acker D, Driscoll S, Brown DA, Jewitt FJ. Cesarean section-related maternal mortality in Massachusetts, 1954-1985. Obstet Gynecol 1988; 71:385-8. 